\title{
Bevacizumab/Paclitaxel Regimen
}

National Cancer Institute

\section{Source}

National Cancer Institute. Bevacizumab/Paclitaxel Regimen. NCI Thesaurus. Code C138050.

A chemotherapy regimen consisting of paclitaxel and bevacizumab, used as a treatment for recurrent and metastatic breast cancer. 